\title{
COMMENT
}

\section{The devil's in the details}

\author{
Gregory A Petsko*
}

The Health Care Reform Bill that was recently passed by the US Congress and signed into law by President Obama has admirably simple goals: to provide health care benefits to some $30+$ million Americans who currently have none, and to begin to control the spiraling cost of health care, which is threatening to make a shambles of the US economy. But, as my mother was fond of saying, the devil's in the details, and at 2,562 pages of almost unreadable prose, there are a lot of details for the devil to hide in. This shouldn't detract from the extraordinary achievement of President Obama and the Democratic Party leadership in Congress; by simply getting the bill passed, they accomplished something that presidents since Theodore Roosevelt have failed to do.

Still, there is one particular detail that is worth scientists in general - and maybe genome biologists in particular - paying some attention to. It goes by the rather unglamorous name of SA 2688, and it's an amendment to the bill. It was inserted into the final package by Pennsylvania Senator Arlen Specter, a longtime champion of biomedical research and increased funding for the US National Institutes of Health (NIH). The amendment is 8 pages long, so I can't quote it in detail, but here's a summary of what it says.

The amendment creates a program called the Cures Acceleration Network (CAN) within the Office of the $\mathrm{NIH}$ Director (with a 24-member oversight board). CAN is to "award grants and contracts to eligible entities... to accelerate the development of high need cures, including through the development of medical products and behavioral therapies". A high need cure is defined as a product that "is a priority to diagnose, mitigate, prevent, or treat harm from any disease or condition; and for which the incentives of the commercial market are unlikely to result in its adequate or timely development". CAN's functions include: conducting and supporting revolutionary advances in basic research; translating scientific discoveries from bench to bedside; awarding grants and contracts to eligible entities; providing the

*Correspondence: petsko@brandeis.edu

Rosenstiel Basic Medical Sciences Research Center, Brandeis University, Waltham, MA 02454-9110, USA resources necessary for government agencies, private companies, academic institutions, and investigators to develop high need cures; reducing the barriers between laboratory discoveries and clinical trials for new therapies; and facilitating review in the Food and Drug Administration (FDA) for the high need cures funded by CAN.

The board consists of 24 members, serving 4 year terms. At least one individual eminent in each of the following fields will be appointed: basic research; medicine; biopharmaceuticals; discovery and delivery of medical products; bioinformatics and gene therapy; medical instrumentation; and regulatory review and approval of medical products. In an unprecedented move, an additional four individuals from private venture capital firms will also be appointed, as well as eight representatives of disease advocacy organizations.

Finally, ex officio members will include a representative from each of the NIH, the Department of Defense Health Affairs office, the US National Science Foundation, and the FDA, the regulatory body that oversees the safety and effectiveness of medicines and treatments. The Board is to advise the NIH Director on 'significant barriers' to successful translation of basic science into clinical application. The Board will provide recommendations to the Director if such a barrier is identified. If the NIH Director does not accept such a recommendation, he must explain to the Board why he has not done so.

The CAN sets up a series of grant programs designed to facilitate the development of high need cures that are in compliance with FDA standards on the drug development and approval process. Eligible entities include private or public research institutions, academic institutions, medical centers, biotechnology or pharmaceutical companies, disease or patient advocacy organizations, or academic research institutions.

There are three types of awards: first, the Cures Acceleration Partnership Awards, which provide up to $\$ 15$ million per project for the first year, in one lump sum. It seems that additional increments of up to $\$ 15$ million can be applied for in subsequent fiscal years (but it is not clear whether more than one additional year of funding is allowed). The recipient must also come up with non-Federal matching funds in a ratio of $\$ 1$ for each $\$ 3$ of Federal funds received. The matching-fund requirement can be waived by the director. Second, there are the 
Cures Acceleration Grant Awards, which are also funded at up to $\$ 15$ million the first year, with at least one followup funding cycle of up to an additional \$15 million possible. There is no matching requirement for this type of award. Finally, there are the Cures Acceleration Flexible Research Awards, which allow the NIH director to use 'other transactions' besides contracts, grants, or cooperative agreements to carry out the goals and objectives of the award program. No more than $20 \%$ of the total funds available for the CAN program can be spent in this manner. The CAN is authorized at $\$ 500$ million in 2010, with additional funds as required for each of the next 10 years.

On the surface, this sounds like a great idea, and one that might help improve the image of federally-funded scientific research with the general public. But the devil is in the details, and to understand that, I need to take a moment to explain a peculiarity of American civics to my non-US readers.

There are two major kinds of legislation that Congress can pass when it wants to establish new programs: authorizations and appropriations. Authorizing legislation is that "which authorizes the appropriation of funds to implement" laws that create agencies, programs or government functions. It does not give a government agency permission to write a check or enter into a contract. Rather, its purpose is to set parameters for government agencies and programs. An appropriations act, on the other hand, confers budget authority on federal agencies to incur obligations. In other words, authorizing legislation sets policies and funding limits for agencies/programs, whereas appropriations legislation is what a department or agency needs to obtain new money from the government to actually fund that agency or program. In the absence of an appropriation, agencies must find the money they need to satisfy an authorization by taking it away from other funded activities: this is the dreaded 'unfunded mandate' that drives administrators to distraction.

SA 2688 is - you guessed it - an authorization without an appropriation. It requires the $\mathrm{NIH}$ to spend $\$ 500$ million a year for 10 years (about 1.7\% of its current $\$ 30$ billion budget), but it does not provide any new money to pay for it. So the money must come from somewhere, and the big fear among many in the scientific community is that it will come from the pool of individual investigator-initiated research support, which has no single large political constituency to fight for it, rather than, say, some of the large, disease-focused programs that are closely watched over by the patient advocacy organizations. This is a particular problem right now, because the NIH is facing a potential 'budget cliff' in fiscal year 2011, when the stimulus funds that Congress appropriated in response to the financial crisis expire, and the base NIH budget becomes flat again. Bleeding $\$ 500$ million - or even a fraction of it - from the individual research grant pool would turn that cliff into an abyss.

There are various alternatives for 'finding' the money that the community should urge the NIH Director to look into. One would be to allow each of the diseaseoriented Institutes and Centers of the NIH to designate grants and programs they are already funding as CAN programs - provided, of course, that they meet the general parameters of the authorization. That would allow CAN to coexist peacefully with the existing research that NIH supports.

But, whereas I like that idea, I'd like to see another one debated first, because there's a chance that I'd like it even more. It involves transforming the RoadMap program, which is already administered out of the NIH Director's office, into CAN.

The RoadMap was the brainchild of Elias Zerhouni, the former NIH Director (the agency is now headed by Francis Collins, a genome biologist). The purpose was to identify major opportunities and gaps in biomedical research that no single institute at NIH could tackle alone but that the agency as a whole needed to address, to make the biggest impact on the progress of medical research. Doesn't that sound exactly like what CAN is also concerned about? The RoadMap has never received the unqualified support of the biological science community, chiefly because they saw it as taking money and attention away from important fundamental research and channeling it into lower-quality, clinically oriented studies that often didn't go anywhere.

The CAN authorization provides a golden opportunity to reinvent this program in a way that Congress and the disease advocates would both love, while doing some very useful work. What's wrong with that? Well, nothing, but the devil's in the details. Read the wrong way, CAN could turn first-rate biomedical research programs at $\mathrm{NIH}$ and elsewhere into third-rate pharmaceutical endeavors. That would be a disaster, because the Bill greatly underestimates the cost of bringing a therapy to the clinic (almost $\$ 1$ billion for a small-molecule drug, a third to a half of that for a biopharmaceutical), and risks promising the public cures that will take over a decade to materialize. Such an approach would also set the advocates for different diseases in direct competition with one another for this pot of money, which is the major reason I oppose focusing CAN on any one disease or set of diseases.

Why not, instead, take CAN at its word? It wants to accelerate the finding of cures, so let's focus it on the major bottlenecks to going from fundamental scientific discoveries to actual cures, for all diseases.

There are many of these. I think CAN should pick, say, two or three of them and make those its focus for the 
next 10 years. These should be what those three types of grants should be asked to address, and the money should be the money that is currently being spent on the RoadMap. Here are my personal favorites, but there are a few more that could also be imagined:

A major bottleneck is the inability to make analogs of complex organic molecules rapidly, especially those containing more than one asymmetric center. NIH still funds some research on the development of new synthetic methods in organic chemistry, but it used to fund a lot more. This is an opportunity for it to get back into that very important business.

Natural products are still very important sources of drugs, but they are hard to separate from the complex mixtures found in the wild and even harder to characterize and synthesize. CAN could throw some serious resources at the development of better methods to do these things.

Our animal models for toxicity are pretty good, but our animal and cell culture models for many diseases are terrible (this is particularly true for the major neurological disorders). Comparative assessments of all existing disease models, followed a program to fund the development of better ones where needed, would have a major impact on the pace of drug discovery, because such improved models would allow therapeutics to fail much earlier in the drug development pipeline, before expensive clinical trials are initiated.

The blood-brain barrier is one major reason that many pharmaceutical companies are abandoning their programs in central nervous system (CNS) diseases. It is very difficult to predict the CNS availability of a compound in humans without doing actual trials. The blood-brain barrier is a combination of restricted permeability of the brain to compounds in the blood with specific efflux pumps that export many drug-like substances. We need ways to design CNS-available compounds from first principles if we really wish to accelerate the development of cures for disorders such as Alzheimer's disease.

Most biopharmaceuticals are immunogenic, even when they are human proteins, and some of them are seriously so. One of the main reasons is that misfolded or aggregated proteins break tolerance, and the manufacture, storage and delivery of therapeutic biological macromolecules contains numerous opportunities for proteins to denature. Development of improved methods to form and maintain the native structure of these molecules would remove a significant obstacle to their increased use.

There's one more I would strongly suggest, but I don't have room to discuss it here. I've written about it in a commentary in our sister publication, BMC Biology, the flagship journal of the BMC series. The main point I am trying to make is that we should use CAN as an opportunity to energize the biomedical research community to tackle some of the major roadblocks to the development of therapeutics in general. That is, we need to make major improvement to the details of how we do such development, after all, when it comes to such development, the devil is in the details, and if we're going to beat the devil, those details are where we need to focus more effort.

Published: 30 April 2010

doi:10.1186/gb-2010-11-4-117

Cite this article as: Petsko GA: The devil's in the details. Genome Biology 2010, 11:117. 